\title{
Floating corallites: a new ecophenotype in scleractinian corals
}

Received: 10 April 2009/Accepted: 24 July 2009/Published online: 11 August 2009

(C) Springer-Verlag 2009
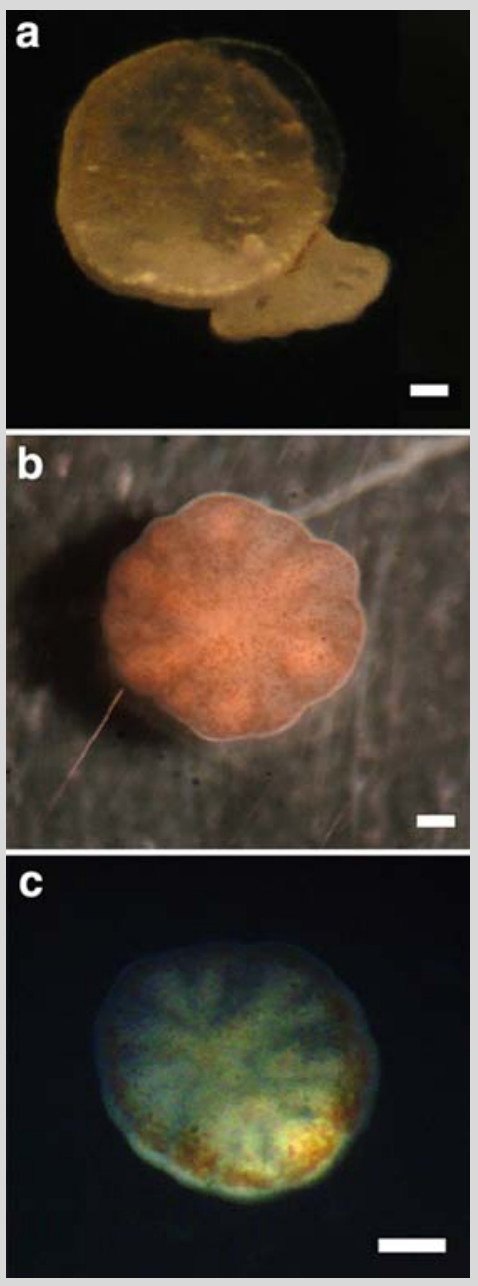

Fig. 1 Downward view on floating ecophenotypes of a Montipora capitata, b Agaricia humilis and c Montastraea faveolata. Scalebars represent $0.10 \mathrm{~mm}$. Note the extending polyp in (a) and the now upward facing zooxanthellae (brown dots) in (b) and (c)
Over the last five years, while working with planulae of several coral species in the Caribbean (Montastraea faveolata, Montastraea cavernosa, Acropora palmata, Siderastrea radians, Agaricia humilis) and Hawaii (Montipora capitata), a previously undescribed floating life-stage of corals was observed in various aquarium settings (Fig. 1). A subset of planulae (3.5-7.0\%) excreted a buoyant skeleton, causing the individual to float upside down on the water surface as tentacles developed pointing downward. Excreted skeletons were larger and flatter than those excreted by benthically settling planulae. Endosymbiontic algae (zooxanthellae) became abundant at the aboral side of the floating corallite, now facing the incoming light. The calcareous skeletons were extremely buoyant and floated back to the surface when submerged in a $0.5 \mathrm{~m}$ deep water basin. While the majority of floating corallites in experimental treatments remained afloat, a subset of individuals $(8-100 \%)$ detached from their skeletons after 3-6 weeks and settled at the bottom where they formed a new skeleton. Because floating polyps possess tentacles and zooxanthellae, planktotrophy and autotrophy both potentially provide supplemental resources beyond lecithotrophy, thereby extending the polyp's competency period in the pelagic environment. Floating corallites have currently only been observed in a laboratory setting. It would be extremely difficult to detect these fragile structures in the field, but without such information, the relative importance of specialized life stages in the population dynamics of corals cannot be assessed. Nevertheless, floating corallites could represent yet another life-history option that allow coral settlers to optimize their survival chances before recruitment in addition to: (1) "de-metamorphosis", whereby settled planulae leave their excreted skeleton on the benthos and resume a pelagic larval form (Richmond 1985); (2) "rambling", whereby settled planulae fail to excrete a skeleton and tumble across the benthos much like the locomotive behavior described for anemones (Vermeij and Bak 2002) and (3) "polyp bail-out" whereby coral polyps separate from a colony and drift a short distance away (Sammarco 1982). All of these observations suggest that the larval life stage of corals includes myriad behaviors that can help increase the probability of successful dispersal and recruitment (Fig. 1).

\section{References}

Richmond RH (1985) Reversible metamorphosis in coral planula larvae. Mar Ecol Prog Ser 22:181-185

Sammarco PW (1982) Polyp bail-out: an escape response to environmental stress and a new means of reproduction in corals. Mar Ecol Progr Ser 10:57-65

Vermeij MJA, Bak RPM (2002) Corals on the move: rambling of Madracis pharensis polyps early after settlement. Coral Reefs 21:262-263

\section{J. A. Vermeij ( $₫)$}

CARMABI, Piscaderabay z/n, Willemstad, Curaçao, Netherlands Antilles

e-mail: m.vermeij@carmabi.org

M. J. A. Vermeij

IBED, University of Amsterdam, Nieuwe Achtergracht 127, 1018 WS Amsterdam, The Netherlands

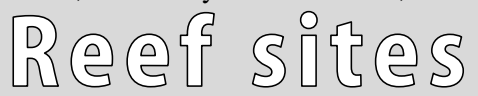

Coral Reefs (2009) 28:987

DOI $10.1007 / \mathrm{s} 00338-009-0535-3$ 